\title{
Comparative Study between Endoscopic Dacryocystorhinostomy and Balloon Catheter Dilatation in Treatment of Chronic Nasolacrimal Duct Obstruction
}

\author{
Mosaad Elsisi, Ismail Elmofty, Ahmed Abdelghany, Alaa Abdelsamie
}

Department of

Otorhinolaryngology, Benha

faculty of medicine, Banha

University, Egypt.

Correspondence to: Alaa Abdelsamie, Department of Otorhinolaryngology, Benha faculty of medicine, Banha University, Egypt.

Email:

alaasalma123.am@gmail.com

Received: 3 July 2020

Accepted: 2 August 2020

\begin{abstract}
:
Background: Epiphora is defined as watering of the eye due to imperfect drainage of tears through lacrimal passages. It may result from a wide variety of causes, the commonest cause is nasolacrimal duct obstruction (NLDO), which may be congenital or acquired. Acquired NLDO may be primary or secondary. Dacryocystorhinostomy (DCR) is an operation that creates a lacrimal drainage pathway into the nasal cavity to facilitate drainage of the previously obstructed excreting system. Aim of the work: The aim of this study is to compare endoscopic DCR and balloon catheter dilation in treatment of nasolacrimal duct obstruction. Patients and methods; A Prospective randomized comparative Study was conducted on 30 patients .15 cases underwent endoscopic DCR while the other cases underwent balloon catheter dilation. Data were analyzed and compared using Z, Chi-square and
\end{abstract}

Fisher exact test. Results: The balloon catheter dilatation is a safe and minimally invasive technique but the endoscopic DCR has a high success rate. Conclusion: The two techniques are acceptable alternatives. The choice of surgery should depend upon patient's preference and availability of resources.

Keywords: Balloon Catheter Dilation, Chronic Nasolacrimal Duct Obstruction, Endoscopic Dacryocystorhinostomy.

List of Abbreviations:

DCR:Dacryocystorhinostomy

NLD: Nasolacrimal duct 


\section{Introduction}

Watering of the eye is an annoying problem embarrassing the patient both socially and functionally. It may result from either lacrimal secretory disorders or lacrimal excretory disorders. It is important to differentiate hyper lacrimation from epiphora. Epiphora is defined as watering of the eye due to imperfect drainage of tears through lacrimal passages ${ }^{(1)}$.

It may result from a wide variety of causes, the commonest cause is nasolacrimal duct obstruction (NLDO) ${ }^{(2)}$, which may be congenital or acquired. Acquired NLDO may be primary or secondary (3). Dacryocystorhinostomy DCR is an operation that creates a lacrimal drainage pathway into the nasal cavity to facilitate drainage of the previously obstructed excreting system. ${ }^{(4)}$

Endoscopic DCR allows direct inspection of lacrimal sac for underlying pathology. Assessment of failure viewed endoscopically, so mistakes can be corrected immediately ${ }^{(5)}$. Also, it can be converted to external DCR in difficult cases or those with lacrimal sac tumors (6). Endoscopic DCR has highly success, but obviously is more invasive. The quest on this front has been to look into the feasibility of using minimally invasive alternatives. With the advent of balloons; several studies have looked at the efficacy of using balloon catheter in such case ${ }^{(7)}$.

\section{Patients and Methods:}

A prospective comparative study was carried out in Benha University Hospitals, Egypt on 30 patients, from October 2016 to April 2018. Informed consents and local Ethical Committee approval had been obtained before the onset of this study.

Inclusion criteria were; distal nasolacrimal passage obstruction, failed conservative treatment and failed lacrimal probing. Presence of epiphora due to presaccal obstruction, Suspicion of malignancy, Radiation therapy to the head and Post traumatic bony deformity of the face were not included.

Totally, 30 patients were enrolled in this study. Group (A) included 15 patients whom submitted for endoscopic DCR. In the other hand, Balloon catheter dilatation was the procedure of choice for group B. Detailed history taking including evaluation of epiphora ${ }^{(8)}$ and nasal examination were performed. 
Both groups were referred to the ophthalmology outpatient clinics for exclusion of presaccal obstruction. Larcimal regurge test was done by Pressure on the lacrimal sac of the diseased eye. So, the regurge through the puncti was noticed, positive regurge test indicates obstructed nasolacrimal duct with patent canaliculi. Purulent regurge indicates chronic dacryocystitis ${ }^{(9)}$.

Lacrimal syringing \&probing tests had been performed for diagnosis and as a trial for treatment. Probing was performed under general anesthesia in children due to lack of co-operation. In adults, a cottontipped applicator soaked in 10\% xylocaine solution left for a few minutes in the medial canthus ${ }^{(\mathbf{1 0})}$. CT scan of the nose \& parnasal sinuses, axial and coronal CT were requested at $3 \mathrm{~mm}$ thickness slices bony window.

In Endoscopic DCR group, mucosal incision started approximately $8 \mathrm{~mm}$ above the insertion of the middle turbinate to lateral nasal wall (the axilla of the middle turbinate). The incision is brought anteriorly for approximately $8 \mathrm{~mm}$ (fig 2 ). A vertical incision is made from the anterior end of previous incision down to just above the inferior turbinate, and then another horizontal incision extends posteriorly to the insertion of the uncinate process.

A Freer elevator was used to lift the nasal mucosal flap keeping the dissection under the mucoperiosteum (fig 3). This mucosal flap was tucked around the anterior end of the middle turbinate to allow further dissection. The thin lacrimal bone covering the posterior part of the lacrimal sac was separated easily from the thick frontal process of the maxilla covering the anterior part of the sac by sickle knife then the lacrimal bone was removed by Blakesley forceps (fig 4), then rhinostomy was enlarged by removal of part of the frontal process of the maxilla.

Incision was done by sickle knife making two horizontal and one vertical incision in between creating anterior and posterior saccal flaps.Inspection of the interior of the sac is important to visualize any stone or F.B. inside the sac. Blakesley forceps was used to remove the central part of the nasal mucosal flap to be coadapted with the performed ostium and saccal flap so the flap rest together without gap.

In Balloon catheter dilatation group, we used angioplasty balloon catheters (fig.6) with suitable diameters $(3 \mathrm{~mm}, 2.5 \mathrm{~mm}$ and $1.5 \mathrm{~mm}$ ) and length of working segment $(20 \mathrm{~mm})$. The deflated balloon 
was inserted with the hard tip of the guide wire just after the balloon tip.

The balloon-guide wire was inserted through the superior or inferior puncti in the same fashion as probing.The advancing end of the balloon was seen in the inferior meatus by help of nasal endoscope (0 or 30 degrees).Standard inflation device was connected to the catheter. The balloon was inflated by a non-toxic colored material to 8 atmospheric pressure (fig.8) for 90 seconds then deflated. Second inflation was done at the same pressure. The catheter was withdrawn only after complete deflation of the balloon. Irrigation was done to ensure the patency of nasolacrimal system. Lacrimal silicone tube was passed through the superior and inferior canaliculi then received under endoscopic vision through the nose.

Eye drops were started in the recovery room contain neomycin and dexamethasone phosphate three times daily for two weeks. Steroid nasal spray and alkaline nasal wash were used for one month ${ }^{(11)}$. The follow up was planned weekly in the first month then monthly for 6 months. Subjective assessment was done by asking the patient about resolution of epiphora; the improvement of patient's symptoms was classified according to Munk scale ${ }^{(8)}$. Objective assessment had been performed by Regurgitation test. Resolution of epiphora and negative regurgitation test were the main criteria of success.

\section{Results;}

The collected data were organized; tabulated and statistically analyzed using statistical package for social science (SPSS) computer package, running on IBM compatible computer, Windows 7 operating system. Quantitative data were represented as mean, standard deviation, minimum and maximum. Qualitative data were represented as frequency and percent distribution.

30 patient in two groups were evaluated. The age of the patients in our study ranged from 4 to 60 years and there was no significant difference (0.09) between endoscopic and balloon catheter dilatation group (Table 1). As regard to the etiology of NLD obstruction, primary acquired NLD obstruction with patent canaliculi (40\%, 26.67\%), Congenital NLD obstruction (20\%, 26.67\%), Mucocele with chronic dacryocystits presented in $(26.67 \%$, 26.67\%) and Pyocele with chronic dacryocysitis $(13.3 \%, 20 \%)$ were reported 
in group A and B respectively with no significant difference $(0.92)$ between both groups (Table 2).

As regard to Muck staging system for epiphora preoperatively, the number of cases were $(4,1)$ Grade I , (3,0) Grade II, $(1,6)$ Grade III , $(4,4)$ Grade IV, $(3,4)$ Grade $\mathbf{V}$ in endoscopic and balloon catheter dilatation group respectively with no significant difference $(0.07)$ between both groups( Table 2) .

As regard to success rate according to Muck staging system for epiphora; the cases were $(9,5)$ Grade $0,(3,2)$ Grade I, $(3,0)$ Grade II, $(0,3)$ Grade III, $(0,2)$ Grade IV, $(0,2)$ Grade $\mathbf{V}$ in endoscopic DCR and balloon catheter dilation groups respectively with significant increase in success rate (0.02) in group A (Table 3)

As regard to success rate according regurgitation test, there were 12 cases (80.0\%) underwent endoscopic DCR in comparison to 6 cases (40\%) underwent balloon catheter dilatation with negative reflux. On the other hand, There were 3 cases (20.0\%) underwent endoscopic DCR in comparison to 9 cases $(60 \%)$ underwent balloon catheter dilatation with positive reflux.

As regard to post-operative complications, 9 cases $(60 \%)$ of balloon catheter dilatation cases had no complication in comparison to endoscopic DCR cases which reported only in one case $(6.67 \%)$ with significant difference (0.02) between them .complications were in the form of mild epistaxis (8), lid ecchymosis (5), adhesions (2) and granulation tissue around the tube (1) .

As regard to success rate in relation to age, the balloon catheter dilatation was better $(40 \%)$ in young age ( $<5$ years $)$ than endoscopic DCR (6, 67\%) which is preferable in older group (18-60 years) (table 4).

Table (1) Comparison between the studied groups as regard to age distribution

\begin{tabular}{|c|c|c|c|c|c|c|}
\hline & $\begin{array}{l}\text { Endoscopic } \\
(\text { no.=15) }\end{array}$ & & $\begin{array}{l}\text { Balloon } \\
(\text { no.=15) }\end{array}$ & & $\begin{array}{l}\text { Mann- } \\
\text { Whitney } \\
\text { test }\end{array}$ & $\mathbf{p}$ \\
\hline & Mean \pm SD & Range & Mean \pm SD & Range & & \\
\hline $\begin{array}{l}\text { Age } \\
\text { (years) }\end{array}$ & $29.4 \pm 16.8$ & $5-60$ & $19.53 \pm 16.65$ & $4-55$ & 1.71 & 0.09 \\
\hline
\end{tabular}


Benha medical journal vol. 38, issue 1, 2021

Table (2): Comparison between the studied groups as regard to Muck staging system for epiphora pre-operative

\begin{tabular}{llllll}
\hline Muck staging & $\begin{array}{l}\text { Endoscopic } \\
(\mathbf{n o .}=\mathbf{1 5})\end{array}$ & No. & $\%$ & $\begin{array}{l}\text { Balloon } \\
(\mathbf{n o .}=\mathbf{1 5})\end{array}$ & P * \\
\hline Grade I & 4 & 26.67 & 1 & 6.67 & 0.07 \\
Grade II & 3 & 20.0 & 0 & 0.0 & \\
Grade III & 1 & 6.67 & 6 & 40.0 & \\
Grade IV & 4 & 26.67 & 4 & 26.67 & \\
Grade V & 3 & 20.0 & 4 & 26.67 & \\
\hline
\end{tabular}

Table (3): Comparison between studied groups as regard to success rate according to Muck staging system for epiphora

\begin{tabular}{llllll}
\hline Muck staging & \multicolumn{2}{l}{ Endoscopic $($ no.=15) } & \multicolumn{2}{l}{ Balloon $($ no. $=15)$} & $P *$ \\
& No. & $\%$ & No. & $\%$ & \\
\hline Grade 0 & 9 & 60.0 & 5 & 33.33 & 0.02 \\
Grade I & 3 & 20.0 & 2 & 13.33 & $(\mathrm{~S})$ \\
Grade II & 3 & 20.0 & 0 & 0.0 & \\
Grade III & 0 & 0.0 & 3 & 20.0 & \\
Grade IV & 0 & 0.0 & 3 & 20.0 & \\
Grade V & 0 & 0.0 & 2 & 13.33 & \\
\hline
\end{tabular}

Table (4): success rate in relation to age.

\begin{tabular}{|c|c|c|c|c|c|}
\hline \multirow[t]{2}{*}{ Age (years) } & \multicolumn{2}{|c|}{ Endoscopic (no.=15) } & \multicolumn{2}{|c|}{ Balloon (no.=15) } & \multirow[t]{2}{*}{$\mathbf{P} *$} \\
\hline & No. & $\%$ & No. & $\%$ & \\
\hline$<5$ & 1 & 6.67 & 6 & 40.0 & 0.02 \\
\hline$<18$ & 5 & 33.33 & 7 & 46.67 & (S) \\
\hline $18-60$ & 9 & 60.0 & 2 & 13.33 & \\
\hline
\end{tabular}




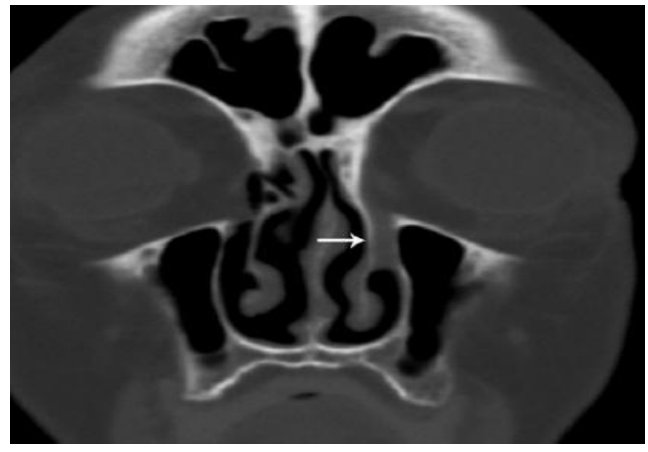

Fig. (1): Coronal image show opacified nasolacrimal duct on the left side.

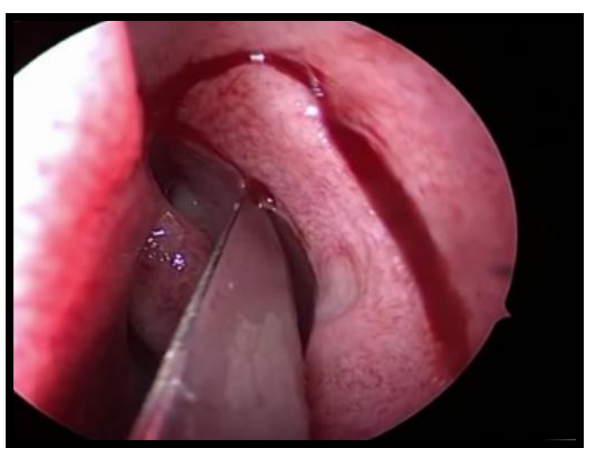

Fig.( 2): The site of incision of nasal mucosa.

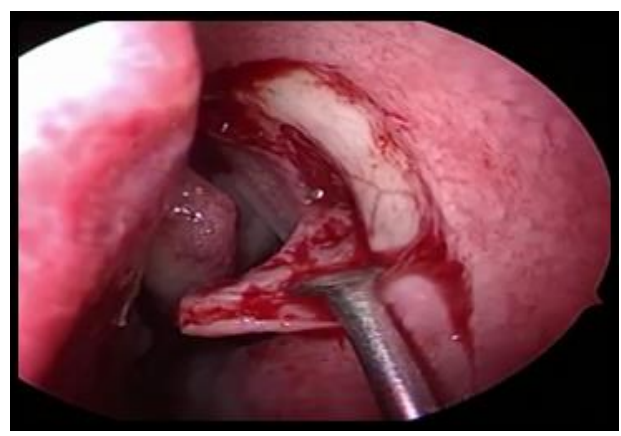

Fig.(3): Dissection of nasal mucosal flap
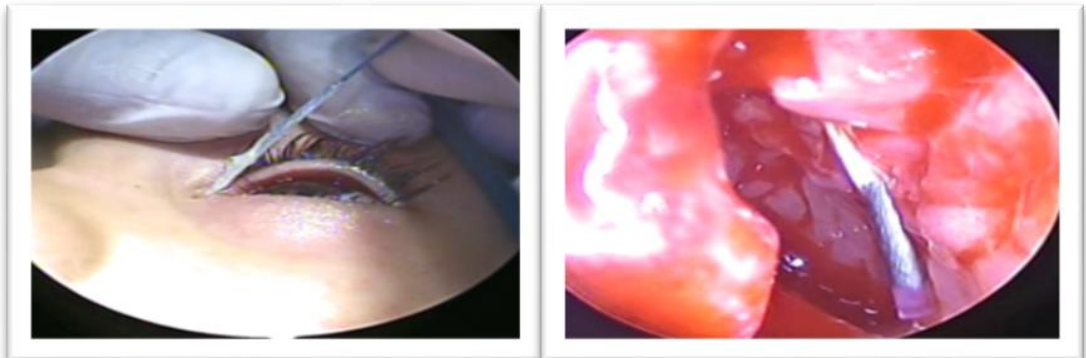

Fig. (7) Insertion of the deflated balloon through the lacrimal passage 


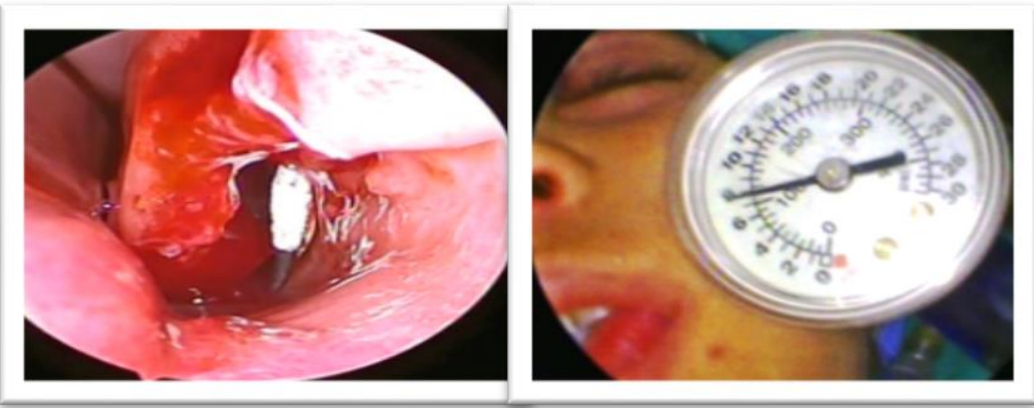

Fig. (8): Inflation of the balloon to 8 atmospheric pressure.

\section{Discussion}

In our study, 6 months of follow-up, success rate according to Muck staging system for epiphora; it was $60 \%$ in group A (endoscopic DCR) in comparison to 33.33 $\%$ in group B (balloon catheter dilatation). There is a significant difference in success rate $(0.02)$.

these results coincides with Sprekelsen and Barberan, $1996^{(12)}$, after 152 cases of endoscopic D.C.R., using the subjective improvement of symptoms and inspection of the tear flow from the drainage site by endoscope, the success rate was $85.5 \%$.Our results were in disagreement with Perry, 1998 (13) who treated 15 obstructed nasolacrimal ducts in adults with balloon dilatation and at 6 months follow up; they reported success rates of $73 \%$ using the Munk scale. Also, Couch and White, 2004 (14) studied 142 partially obstructed nasolacrimal ducts and reported an overall improvement in epiphora using balloon catheter is $56 \%$.

As regarding success rate in relation to age, we found that balloon catheter dilatation results were better in young age (40\%) in comparison to endoscopic $\operatorname{DCR}(6.67 \%)$, while the results of endoscopic DCR were found better In adult and old age $(60 \%)$ as compared to that of balloon dilatation(13.33\%).

Our results collaborates withTao, $2018^{(15)}$ who reported that, children more than 24 months of age who had undergone a previous probing, the success rate greater than $95.1 \%$. But this disagreed only by one study by Perry, $\mathbf{1 9 9 8}^{(13)}$ who reported that, Adult success rate has been noted as $(73 \%)$. As regarding post-operative complication in our study, there were 9 cases $(60 \%)$ of balloon catheter dilatation with no complication in comparison to endoscopic 
DCR cases which reported one case $(6.67 \%)$. There was a significant difference as regard to post-operative complication (0.02) between both groups.

Bleyen et al., $\mathbf{2 0 0 7}^{(7)}$ reported that the only major complication during balloon DCR was a single case of orbital emphysema.

It was initiated with a forceful sneezing and managed successfully by a conservative approach.

Karim et al., 2011 ${ }^{(16)}$ found no serious complication in their study, except only two patients in endoscopic DCR group with postoperative haemorrhage requiring conservative treatment.

Khan et al., $2011^{(4)}$ reported that there was moderate bleeding in $20 \%$ cases of endoscopic DCR but Tsirbas and Wormald PJ, $\mathbf{2 0 0 3}^{(17)}$ reported a rate of 3 $\%$ for such condition.

\section{Conclusion:}

The two techniques are acceptable alternatives. The balloon catheter dilation is a safe, minimally invasive technique and better in children, but endoscopic DCR has better success rate and better in adult and old age. The choice of surgery should depend upon patient's preference and availability of resources.

\section{References}

1. Cokkeser Y, Evereklioglu C, Er H. Comparative external versus endoscopic dacryocystorhinostomy: Result in 115 patients (130 eyes) Otolaryngol Head Neck Surg. 2000;123 (4) 488-91 .

2. Shikha Nailwal, Arvind Ram, Neelima Mehrotra, Rohit Sharma, Akhil Agarwal,. "Comparison of External and Endonasal Dacryocysto-Rhinostomy in Acquired Nasolacrimal Duct Obstruction. jemds 2015. 4(14)2263-2273.

3. Saha R,Sinha A and phukan JP. Endoscopic versus external DCR. Compartive Study.Nigger med J 2013 ;54(3): 165-9.

4. Khan MK, Hossain MA, Hossain MJ, Al-Masud A, Rahman MZ. Comparative study of external and endoscopic endonasal dacryocystorhinostomy for the treatment of chronic dacryocystitis. JAFMC Bangladesh. 2011.7(2):15-7.

5. Anijeet D, Dolan L, Macewen CJ. Endonasal versus external dacryocystorhinostomy for nasolacrimal duct obstruction. Cochrane Database Syst Rev. 2011;(1):CD007097.

6. Abnormalities of the lacrimal secretory and drainage systems. American Academy of Ophthalmology, section 7, 2012-2013 p. 268.

7. Bleyen I, van den Bosch WA, Bockholts D, Mulder P, Paridaens D. Silicone intubation with or without balloon dacryocystoplasty in acquired partial nasolacrimal duct obstruction. Am $J$ Ophthalmol. 2007;144(5):776-780.

8. Munk PL, Lin DT, Morris DC. Epiphora: treatment by means of dacryocystoplasty with balloon dilation of the nasolacrimal drainage apparatus. Radiology. 1990;177(3):687-690.

9. Jones LT: Anatomy of the tear system. In Holly FJ, Lemp, MA (Eds):The preocular tear film and dry eye syndromes. Int Ophthalmol Clin 2008;. 2(1): $31-55$.

10. Thongthong K, Singha $P$ and Liabsuetrakul T. Success of probing for congenital nasolacrimal duct obstruction. J Med Assoc Thai 2009 . 92 (12). $1646-50$ 
11. Julian D. Perry, Marlon Maus, Thaddeus S. Nowinski, , Robert B. Penne, M. Balloon catheter dilation for treatment of adults with partial nasolacrimal duct obstruction: a preliminary report. The American Journal of Ophthalmology. 1998;126( 6) 811-816.

12. Sprekelsen MB, Barberán MT. Endoscopic dacryocystorhinostomy: surgical technique and results. Laryngoscope. 1996;106(2 Pt 1):187-189.

13.Perry J.D., Maus M., Nowinski T.S., Penne R.B : Balloon catheter dilation for treatment of adults with partial nasolacrimal duct obstruction: a preliminary report. Am. J. Ophthalmol;. 1998, 126(6):811-816

14. Couch S.M., White W.L : Endoscopically assisted balloon dacryoplasty treatment of incomplete nasolacrimal duct obstruction. Ophthalmology; 2004, 111(3):585-589.

15. Tao S., Meyer D.R., Simon J.W: Success of balloon catheter dilation as a primary or secondary procedure for congenital nasolacrimal duct obstruction. Ophthalmology; 2002, 109(11): 21082111.

16. Karim R, Ghabrial R, Lynch TF, TangB: A comparison of external and endoscopic endonasal dacryocystorhinostomy for acquired nasolacrimal duct obstruction. Clin Ophthalmol 2011; 5:979-89.

17. Tsirbas A, Wormald PJ: Endonasal dacryocystorhinostomy with mucosal flaps. Am 2003; 135(1):76-83.

To cite this article: Mosaad Elsisi, Ismail Elmofty, Ahmed Abdelghany, Alaa Abdelsamie Comparative Study between Endoscopic Dacryocystorhinostomy and Balloon Catheter Dilatation in Treatment of Chronic Nasolacrimal Duct Obstruction. BMFJ 2021;38(1):55-64. DOI: $10.21608 / \mathrm{bmfj} .2021 .34552 .1284$ 